\title{
Exploration and Practice on New Mode of Industry Training Base and Professional Training Base Combination*
}

\author{
Hu Bin \\ Department of Electrical Engineering, Zhengzhou Electric Power College, ZhengZhou, 450004 \\ frsa@163.com
}

\begin{abstract}
Practical teaching system construction is an important content in national vocational colleges construction. The introduction of industry support, cooperation with enterprises to build a training base, is the main way to improve the conditions of vocational practice teaching. In the building of training bases in Henan Electric Power Company and professional training room, considering the characteristics of each of the training rooms, combined with higher vocational education tallent training, build a new model of training base that not only meet the training requirements of enterprise training base, but also adapt tothe power professional highly skilled talent training.

Index Terms - training base, college-enterprise cooperation, practice teaching
\end{abstract}

\section{Introduction}

The construction of practical teaching system is an important content in national vocational colleges construction. Talent training mode empasis on pratical, open, vocational in teaching process and the crucial aspects are experiment, training and internship. Since 2008, the department of electrical engineering has established three training bases such as substation maintenance, substation operation and power marketing, eight professional training rooms in total. According to the spirit of the relevant documents of the Ministry of Education, the department of electrical engineering has buit a new training model which combines the enterprise training demand with electrical professional talent cultivation. The new training model has sized the opportunity of Henan Electric Power Company training base construction and colloge professional development reform, it targets students' skill cultivation and builds curriculum according to assignment.

2. The construction idea based on the mode of Industry training base and professional training base combination.

As the main site in industry skill talent cultivation, industry training base is the main training site of job skills training and the main way to cultive talent within industry[1]. The power industry is pursuing further improvement of management level. In addition, it is increasing effectiveness and decreasing numbers. In the context, power training base undertakes the mission of generalizing new top products, new technologies, new skills and improving the skill level of industry workers.

As the main site in cultivating vocational talent, college professional training base cultivates students' practical skills and integrates theory teaching class and practical teaching site. It has changed into the main site in school teaching, in addiation, it is a site which combines study and work instead of single skill training. Operating in teaching; studying in operating. Adding the operation training to theory teaching is to ensure the learner participate in work while they are studying theory and consolidate, use, review the learned theory in operation, moreover, it supply training of pratical jobs kills. After that, learners gets improvement through theory studying. So, a transformation which is from beginner to expert to qualified job occupation occurred by means of theory promotion [2-3].

So, the combination mode of industry training base and professional training base should satisfy the characters which are meeting the professional talent training demand, servicing for teaching, according to teaching rules, maintaining teaching on one hand, should adapt to the demand of enterprise skilled talent training whose teaching is according to enterprise skilled training demend to complete training assignment on the other hand.

In the combination mode construction, first, we should have the profound understanding in the size of training base, equipment and specific work type, the demand of training environment, the concrete scheme of skilles training, the need of enterprise. Based on this, for improving the quality of the talent training, we should seek the common points, obey teaching rules, set up the idea of the combination of work and study, design practical teaching according to manufacturing process.

3. The construction principles of the mode of Industry training base and professional training base combination

\section{1) Synthesis principle}

According to the actual requirements of enterprise posts, power enterprises training base should strengthen basic skills

* Professional Reform Comprehensive Pilot Project of Henan Province in 2012, The Project of Central Financial Support to Enhance the Professional Services Industry Capacity. 
training, professional skills training and corporate culture, ask students to master professional skills, be familiar with post standard and process, firm basic skills, strengthen students' ability of failure analysis and overcome, enhance discipline and teamwork. Training includes basic operation, basic technics, basic skill training, professional failure analysis and overcome, synthesis skill training, corporate culture, post standard and work rules. All the training should obey the actual process of manufacturing and business completely.

As the main site in cultivating professional talent, college professional training base serves professional teaching and cultivates students' practical skills and integrates theory teaching class and practical teaching site. According to the requirements of talent training plan, it should combine theory with operation in teaching, formulate teaching content on the basis of actucal work, join teaching to actucal work. Operating in teaching; studying in operating. In addiation, it should emphasizes operation in teaching and consolidate theory and skills further in operation. In this way, can the students meet the post requirements from adaptability to acquaintance to familiarity.

In the construction, we should consider enterpeise training requirements and professional teaching requirem - ents, form manufacture-teaching committee to demonstrate scheme and communicate frequently. Furthermore, we should lister to enterpeises' suggestions on layout, equipment selection, training scheme, teachers and talent training mode. Finally, actualize the new mode of teaching-training unity and classoperation unity.

\section{2) Science principle}

Enterprise training serves enterprise workers who have a certain of theory and and practical skills. The training is study and training of specific equipment, technology, production and management process. It requires trainees who have a certain of knowledge and skills to master professional skill, improve work abilities and satify work requirements in similar work place and actual equipment.

In accordance with the training plan for training students, despite some theoretical knowledge and professio -nal skills training, the students accept new equipment, knowledge, skills and still need accept these new things and places which is an "cognitive-familiar-master-apply" process.

Different objects have different basic training, requirements and purposes. The new model construction ask us obey education law and learning rules to show science principle. The trainees should be arranged in actual work environment based on the content of the training and the training process follows the actual work process. For the first time in training students, give an introduction of learning background, the application site, the use of equipment, skills requirements and technics requirements. Then, explain the learned professional knowledge to make sure students complete the whole process wich is from cognitive, familiarity, reflection to practical use. Finally, meet the cultivate requirements.

\section{The construction issues of the mode of Industry training base and professional training base combination}

1) Training teachers' relocation and the construction of teachers

In the curriculum structure of combination of basic theory, professional basic and professional course, make sure the theory system is predominant and cooperate with training, pratice and designing. Besides, match training and pratice to theory course. After professional theory studying, the students can utilize professional knowledge in operation, be familiar with equipments, get training skills and complete task in specific rules.

The main training teachers are lab assistants whose obligation are managing lab, maintaining equipments, preparing teaching, and carrying out experiments teaching with instructors[4]. The lab assistants don't take part in theory teaching.

The new vocational education requires that training base is not only operation teaching site but also where profession -al and basic courses carried out. The obligation of original training teachers have changed greatly. Besides managing lab, they participate in course teaching and are familiar with the courses links which includes location, content, design, requirements, projects and evaluation. Training teachers have no differences in obligation with the theory teachers.

As the training rooms increasing and training projects is more and more professional, more teachers will charge the training management. There will be little defferences between theory teachers and training teachers, even disappear. So, we should relocate training teachers and establish new management rules and methods.

Training teachers are also in charge of the enterprise training task. They should master solid theory and have a high level in operation skills. Only this can they satisfy enterprises' requirements.

In the construction of the mode of training base, teachers construction is the most important part. At the beginning, we should select teachers who take part in the preparation. They take part in all the process which are planning, equipments selection, post allocation, products tender, equipments debugging, training material, course development, teachers training. Finally, they are aware of design concept, equipment parameters, function, training skill types and methods deeply about training base. Moreover, we invite technologists as the part-time teachers who participate in training and help the training teachers grow better.

\section{2) The curriculum construction of the combination mode of training base}

The combination mode of training base not only brings production facilities, manufacture technics, vocational and training environment but also supplies development conditions 
and substance foundation to professional courses. We form manufacture-teaching committee with enterprise experts and formulate talent training plans together which unify teaching content and post core abilities. Develop teaching content about typical manufacturing process on basis of actual manufacturing process[5-7]. The target of enterprise post training is the target of practicing teaching; the process of enterprise post training is the process of practicing teaching; the form of enterprise post training is the form of practicing teaching. Let the work task integrate into teaching task and bring actual manufacturing task to class. Practice actual problem and connect the teaching and post task.

Power correlated major in Zhengzhou Electric Power College connects with industry development and cooperate with enterprise. In the construction of combination mode, power correlated courses have been resolved and recombination. The courses have changed into courses which are corresponding to post requirements. In the pratice teaching, the teachers should combine the content with post requirements and select typical work task which is advanced, operable and practicable. In the construction of teaching material, we should unite the enterprise, invite enterprise ecperts to participate in teaching material compilation, introduce enterprise technique standard and rules. On base of these, compile a series of professional core teaching material which emphasize operable and practicable according to teaching rules.

\section{3) The organization and actualization of teaching}

Enterprise training base serves enterprise workers who are trained in one-to-one training environment. In training process, there are different requirements about different job post. The vocational education course should be organized with work task, adopt the combination of work and study, break the team-class-time about teaching form. There are still class, but training carried on personally or in small team instead of whole class together. Courses carried on in the form of work process instead of theory led. Study time adopts flexible arrangement on the basis of the task.

\section{4) Systemic warrant}

The construction and running of training base is a new mode which combines college with enterprise to achieve win- win situation. We should consider both the requirement $-\mathrm{s}$ in construction, running, management, break the original management, publish new detailed and strict system to make sure running effect and not lack of teaching target. Only this, can we ensure the students' learining and enterprise training.

\section{Conclusion}

The construction of the new mode is one of the exploration which is under the combination of college and enterprise by Zhengzhou Electric Power College. The exploration is about training and studying. The emphasis of vocational college in improving teaching conditions, highlight teaching feature and enhance teaching quality are strengthening practice teaching condition, completing practi ce teaching management system, deepening reform of prac tice teaching. In the reform of Electric Power of HeNan training base construction and college major construction, we sized content development and system innovation. For cultivating high-quality skilled talent to satisfy enterprise, we should make sure meet the requirement of skill training in condition, develop resource advantage in running system, arouse the enthusiasm of teaching and studying. We has explored the reform of pratice teaching system and strive to be carried out.

\section{References}

[1] C. Zhang, X Wang, "Exploration and Practice on Grid Enterprise Traning Base Construction", Management Forum, March, 2010.

[2] L. Zhu, Z. Fan, "Strengthen Practice Teaching and Improve Students' Comprehensive Vocational Abilities", China Education Science, April, 2005.

[3] Y. Zhu, W. Yu, "The Innovation of Education Curriculum Mode and Concept Reconstruction of Training Base", Chinese Vocational and Technical education. Vol. (8), 2009.

[4] X. Feng, "Based on Pratice Teaching to Enhance Training of innovative Talent”, China Electric Power Education, vol (5), 2008.

[5] H. Nan, "Discussion on the Purpose of Modern Vocational Education", Technical Education, Vol. (12), 2005.

[6] Q. Sun, "Strengthen Practical Teaching Management to Improve the Quality of Teaching Practice", Changchun University of Technology Journal, Vol. (02), 2006.

[7] R. Yang, "Exploration on New Mode of College and Enterprise Combination about Campus Productive Training Base Construction", Vocational and Technical Education, Vol. (5), 2012. 